\title{
Incidence and Prevalence of Stroke and its Risk Factors in the Philippines: A Systematic Review
}

\author{
Maria Epifania V. Collantes, MD, MSc, ${ }^{1}$ Yves Miel H. Zuñiga² and Deinzel R. Uezono ${ }^{3}$ \\ ${ }^{1}$ Department of Neurosciences, College of Medicine and Philippine General Hospital, University of the Philippines Manila \\ ${ }^{2}$ University of the Philippines Manila \\ ${ }^{3}$ College of Public Health, University of the Philippines Manila
}

\begin{abstract}
Background. Various epidemiologic studies reported different stroke incidence and prevalence rates in the Philippines. Thus, there is a need to synthesize existing information on these indicators to depict more accurate evidence on the burden on stroke in the country.
\end{abstract}

Objective. The objective of this systematic review is to provide evidence on the incidence and prevalence of stroke in the Philippines, as well as its associated risk factors.

Methods. PubMed and HERDIN were searched for available full-text Philippine epidemiologic studies on stroke incidence and prevalence, whether population or hospital-based, and its associated risk factors. We used three tools for risk of bias assessment, namely, the Newcastle Ottawa Scale for cohort studies, the Quality assessment checklist of Hoy et al. for cross-sectional prevalence studies, and the AXIS tool for general cross-sectional studies.

Results. A total of 14 studies were included in this review. Based on these studies, the national stroke incidence rate ranged from $3.95 \%$ to $5.61 \%$, while the national stroke prevalence rate ranged from $0.486 \%$ to $6.0 \%$. Hypertension remains the commonly reported risk factor of stroke alongside diabetes, smoking, and high cholesterol level.

Conclusions. Despite limitations, we were able to perform a complete assessment of the risk of bias in included studies which provide information on the studies with reliable information. Based on this systematic review, there is variability on data and limited studies on the national epidemiology of stroke in the Philippines. It is recommended that the national government consider establishing a system such as a national registry for better data collection and analysis.

Keywords: systematic review, stroke, prevalence, incidence, Philippines, epidemiology

\section{INTRODUCTION}

Corresponding author: Maria Epifania V. Collantes, MD, MSc Department of Neurociences Philippine General Hospital

University of the Philippines Manila

Taft Avenue, Ermita, Manila 1000, Philippines

Email: mvcollantes@up.edu.ph

\section{Rationale}

The Philippines currently has a population of 101 million Filipinos. ${ }^{1}$ It has a young population with $90 \%$ in the age group below 55 years old. Only 10\% are in the age group above 55 years old. ${ }^{2}$ Stroke is considered the third leading cause of deaths with a crude death rate of 58.1 per 100,000 (equivalent to 60,277 deaths), next to the diseases of the heart and malignant neoplasms, among Filipinos. In the latest available Philippine Health Statistics (2016), it was reported that more than half (54\%) of those who have died from stroke failed to seek medical attention. ${ }^{3}$ Furthermore, Filipinos were observed to have died from the same kinds of diseases, particularly ischemic heart diseases, cancer, and stroke for the past two decades. ${ }^{3}$ This burden is further worsened by different challenges in the health system. The lack of 
medical attendance is secondary to the disintegration of the once integrated referral system involving both public health services and hospital services. ${ }^{4}$ The cited underlying reason behind this is the overlap in the mandates of the Department of Health $(\mathrm{DOH})$ and the local government units (LGUs), as a result of devolution. ${ }^{4}$ Other challenges that contribute to the growing burden of stroke in the country include inadequate service delivery and support to the different sectors particularly the poor and the underprivileged. Furthermore, the financial burden of Filipinos to paying for these health services remains to be high. These factors further push mortality and disability rates due to stroke higher among Filipinos. ${ }^{5}$ On top of these, access to information in depicting the real burden of stroke remains a challenge.

Various epidemiologic studies reported different stroke prevalence and mortality rates. Hospital-based epidemiologic studies may not provide the real burden of the disease because not all patients-at-risk and patients diagnosed with stroke seek medical consultation. On the other hand, communitybased questionnaire studies may not capture the stroke prevalence because of crucial factors such as displacement or migration of people and the lack of confirmation of the disease by trained medical personnel. While there have been several studies on stroke conducted in the Philippines, a clearer picture of the national stroke burden is yet to be established and one of which is through synthesized evidence on the prevalence and incidence of stroke in the country. This systematic review was performed to provide evidence on the incidence and prevalence of stroke and associated risk factors in the Philippines.

\section{METHODS}

This review involved processes from study selection to data collection where consensus from the reviewers was achieved. The protocol was registered in PROSPERO (CRD42020205842). The conduct of the systematic review observed the recommendations of the Preferred Reporting Items for Systematic Reviews and MetaAnalysis (PRISMA). ${ }^{6}$

\section{Search Strategy}

For PubMed, we used the search terms Philippines and stroke as well as its other terminologies: cerebrovascular disease, cerebral infarction, ischemic stroke, intracerebral hemorrhage, and subarachnoid hemorrhage. For HERDIN, since all studies indexed were already in the Philippines, we only used MeSH terms for stroke. The search was performed from inception to 12 April 2020. No restriction on the year of publication was observed.

\section{Information Sources}

Two databases were utilized, namely, PubMed and HERDIN. SCOPUS and WPRIM were searched, and no additional relevant studies were obtained. Background references and citations were identified when possible to relevant articles.

\section{Eligibility criteria}

Any epidemiologic study, either population or hospitalbased, with included participants of at least 18 years old and looking at the prevalence, incidence of stroke, and its associated risk factors in the Philippines, were included in the review. Only studies with accessible full-text articles were included.

\section{Study selection}

Studies from reference chasing, suggestions from experts, and systematic search were managed in EndNote for deduplication. The final list of abstracts and full text, on the other hand, were then uploaded in Covidence.

Two reviewers independently assessed the title and abstract of studies using Covidence based on the systematic search and manual search of references. All cases of disagreement regarding the decision for inclusion were resolved through consensus. All studies eligible for fulltext screening were also reviewed independently by the two reviewers. Disputes in the decision were resolved through consensus as well.

\section{Data collection process}

Data were obtained using a developed data extraction tool. Two reviewers independently extracted data from eligible studies. Disagreements were resolved through consensus. Data extracted from included studies were study design including sampling methodology, if any, characteristics and number of study participants, outcome measures, and methods of identifying stroke.

\section{Risk of bias in individual studies}

The risk of bias in eligible studies was assessed using the Newcastle Ottawa Scale for cohort studies and the Quality assessment checklist of Hoy et al. for cross-sectional prevalence studies. ${ }^{7,8}$ For cross-sectional studies that did not aim to look at the prevalence of stroke and its risk factors, the AXIS tool for assessing general cross-sectional studies was used. ${ }^{9}$

For the Newcastle Ottawa Scale, the following thresholds were used based on the Agency for Healthcare Research and Quality. If criteria for certain domains has not been met, it will be downgraded to the next lower quality. ${ }^{10}$

- Good quality: 3 or 4 stars in the selection domain AND 1 or 2 stars in comparability domain AND 2 or 3 stars in outcome/exposure domain

- Fair quality: 2 stars in the selection domain AND 1 or 2 stars in the comparability domain AND 2 or 3 stars in outcome/exposure domain

- Poor quality: 0 or 1 star in selection domain OR 0 stars in comparability domain OR 0 or 1 stars in outcome/ exposure domain 
For the quality assessment by Hoy et al., the following scores indicate the overall risk of bias in the individual study. ${ }^{7}$

- Low risk: 0-3

- Moderate risk: 4-6

- High risk: 7-9

\section{Summary measures and synthesis of results}

Data collected include incidence, the prevalence of stroke, and its risk factors, either in percent or per 100,000 persons. Data obtained from eligible studies have undergone qualitative synthesis.

\section{RESULTS}

\section{Study selection}

The search that was carried in PubMed and HERDIN yielded a total of 132 records. At the same time, two additional studies were determined based on a manual search of references in consultation with a clinical expert in stroke. Two duplicate studies were removed, and among the 132 studies left, we identified 20 studies as potentially relevant. These 20 studies underwent independent full-text screening. After the assessment, seven studies were excluded, while 13 were eligible for inclusion. (Figure 1)

\section{Description of studies}

\section{Included Studies}

\section{Study Design}

Ten studies had a cross-sectional study design, four of which are hospital-based epidemiologic studies ${ }^{11-14}$ while six were population-based surveys. ${ }^{15-20}$ Three studies had a cohort study design ${ }^{21-23}-$ two prospective ${ }^{21-22}$ and one retrospective. ${ }^{23}$ Two studies came from hospital-based cohorts ${ }^{21,23}$ while one came from a population-based cohort. ${ }^{22}$

\section{Study Participants}

Participants in included studies all comprised of adults meaning that an individual must have been at least 18 years old by the time of the study. Among population-based studies, two studies ${ }^{15,17}$ included individuals that were at least 18 years of age while five studies included individuals that were at least 20 years of age. ${ }^{16,18-20,22}$ On the other hand, all of the hospital-based studies enrolled individuals that already had a diagnosis of stroke or identified risk factors. ${ }^{11-14,21,23}$

\section{Study Duration}

Included studies were conducted as early as the year 1988 and as recent as the year 2019. (Appendix Table 1). One population-based cohort study had a follow-up duration of four years while the two hospital-based cohorts had a follow-up period of five months to 12 months, respectively. ${ }^{21-23}$
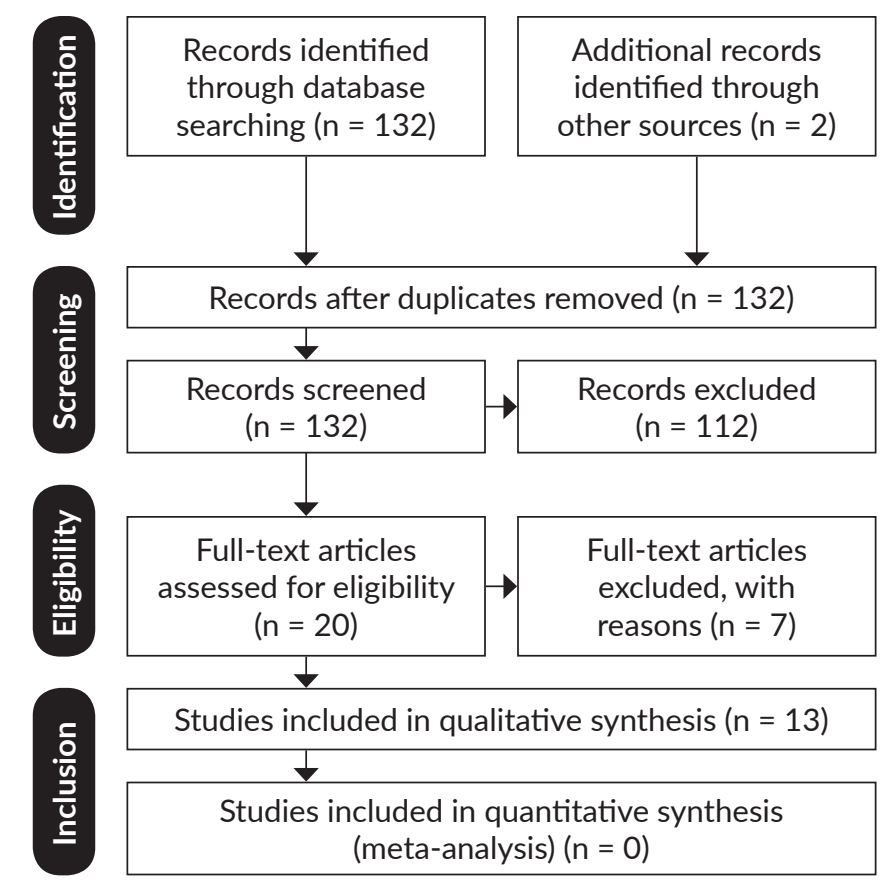

Figure 1. PRISMA Flow Diagram for literature search. ${ }^{6}$

\section{Outcomes}

Prevalence, incidence, and risk factors of stroke were measured in the included studies. Seven of the included studies measured prevalence ${ }^{15-20,22}$ of stroke while one study reported stroke incidence. ${ }^{21}$ Four studies determined the prevalence of stroke according to its classification as ischemic, hemorrhagic, and transient ischemic stroke. ${ }^{11,13,14,24}$ In one study, cases were not identified as either of the three classifications despite patients manifesting symptoms of cerebrovascular disease due to lack of CT scan result. ${ }^{14} \mathrm{~A}$ total of 10 studies measured the prevalence of risk factors of stroke among Filipinos. The risk factors included in this study are hypertension, current smoker, diabetes mellitus (by fasting blood glucose and with or without a history of the disease), a cholesterol level of more than $200 \mathrm{mg} / \mathrm{dL}$, lowdensity lipoprotein (LDL) of more than $130 \mathrm{mg} / \mathrm{dL}$ and obesity (body mass index or BMI is more than 30 ).

\section{Excluded Studies}

Two studies were excluded as there were no reported outcomes of interest specific to the Philippines. ${ }^{24-25}$ Three studies were excluded because data reported in these studies were referring to primary studies that were already included..$^{5,26-27}$ This was done to avoid double reporting of prevalence/incidence. Two studies were also excluded as the described study participants were not the population of interest, which should be adult Filipinos..$^{28,29}$

\section{Risk of bias of individual studies}

The results of the risk of bias assessment for both cohort studies and prevalence studies can be seen in Appendix 
Table 1. Incidence of stroke among included studies (Abola, 2017) ${ }^{21}$

\begin{tabular}{ccc}
\multirow{2}{*}{ Year } & \multicolumn{2}{c}{ Total } \\
\cline { 2 - 3 } & Incidence & $\mathbf{9 5 \%} \mathbf{~ C l}$ \\
Year 1 & 3.95 & - \\
Year 2 & 4.26 & $1.86-6.61$ \\
Year 3 & 4.55 & $2.09-6.94$ \\
Year 4 & 5.61 & $2.64-8.48$ \\
\hline
\end{tabular}

Table 2. Prevalence of stroke among included studies

\begin{tabular}{|c|c|c|c|c|c|c|}
\hline \multirow{2}{*}{ Study ID } & \multicolumn{2}{|c|}{ Male } & \multicolumn{2}{|c|}{ Female } & \multicolumn{2}{|c|}{ Total } \\
\hline & Prevalence & $95 \% \mathrm{Cl}$ & Prevalence & $95 \% \mathrm{Cl}$ & Prevalence & $95 \% \mathrm{Cl}$ \\
\hline Sy, $2003^{19}$ & - & - & - & - & 6.0 & - \\
\hline Dans, $2005^{16}$ & 2.1 & - & 1.7 & - & 1.9 & - \\
\hline Navarro, $2005^{17}$ & 0.663 & $0.514-0.843$ & 0.311 & $0.214-0.439$ & 0.486 & $0.395-0.593$ \\
\hline Roxas Jr, $2007^{18}$ & - & - & - & - & 1.4 & - \\
\hline Soria, $2007^{22}$ & 6.08 & $3.83-8.36$ & 5.02 & $3.10-6.94$ & 5.51 & $4.04-6.98$ \\
\hline Sy, $2012^{20}$ & 1.2 & $-1.8-4.2$ & 0.7 & $-2.0-3.4$ & 0.9 & $-1.1-2.9$ \\
\hline Castillo $2019^{15}$ & - & - & - & - & 2.6 & - \\
\hline
\end{tabular}

Tables 2A, 2B and 2C. For the three cohort studies ${ }^{21-23}$, all were assessed to have a high risk of bias based on the threshold used for converting the scores of the Newcastle Ottawa Scale. A common concern found in the studies was the lack of control for confounding factors such as age, sex, and socioeconomic status in either the design or analysis of the study. ${ }^{21-23}$ Furthermore, one study did not describe the derivation of the non-exposed cohort. ${ }^{23}$

For cross-sectional prevalence studies, all studies included in the risk of bias assessment had a low overall risk of bias. ${ }^{11-14}$ This means that all studies conducted had acceptable internal and external validity based on the tool used. Meanwhile, several issues were noted in the two cross-sectional studies that did not look at the prevalence or incidence of stroke. ${ }^{11,14}$ Sample size justification was not found to be present in all four studies, leading to possible less conclusive results. ${ }^{11-14}$ Most studies utilized data from all eligible participants based on a period.

Furthermore, issues in the determination of the sample population were noticed, specifically in terms of random sampling. ${ }^{11-14}$ Also, since hospital records were used, epidemiologic factors or characteristics observed may be more representative of more severe stroke cases than milder ones that may be observed when done in the community or population-wide studies. Selective reporting of results was observed as well in some studies ${ }^{12,13}$, for instance, reporting only stroke risk factor distribution in males. Ethical approval or consent was not stated nor described as well concerning the use of individual hospital records. ${ }^{11-14}$

In general, it was also observed that many reported data by the studies lacked reporting of either a standard deviation, standard error, or appropriate confidence intervals. Hence the precision of the results cannot be assessed.

\section{Results of individual studies}

\section{Incidence of Stroke}

One study in the review measured the incidence of stroke. $^{22}$ Outpatient Filipinos aged 45 years and above were included in the study and incidence of stroke among said population was found to be between $3.95 \%$ to $5.61 \%$ based on the four-year follow-up. Further data on the study can be found in Table 1.

\section{Prevalence of Stroke}

Seven studies estimated the prevalence of stroke. ${ }^{15-20,22}$ All the national surveys included adult subjects aged at least 18 years and above. Out of these records, four studies measured the prevalence of stroke in terms of sex distribution. ${ }^{16,17,20,22}$ All four studies noted a higher prevalence of stroke among males than in females. Values computed for stroke prevalence ranged from as low as 0.486 to as high as $6.0 .{ }^{17,19}$ Data from these studies are detailed in Table 2.

Four studies were able to record frequencies of stroke subtypes: ischemic, hemorrhagic, and transient ischemic attack. ${ }^{11-14}$ In one study, cases were identified to manifest symptoms but were not identified due to the absence of a CT scan result. ${ }^{14}$ All four studies ${ }^{11-14}$ recorded a higher prevalence of ischemic stroke than hemorrhagic stroke among Filipinos, as presented in Table 3.

\section{Risk factors of stroke}

On the other hand, ten studies ${ }^{11-13,15,16,19-23}$ noted the prevalence of different risk factors of stroke among Filipinos. Hypertension ${ }^{11-13,15,16,19-21,23}$, diabetes ${ }^{11-13,15,16,19-23}$ and smoking ${ }^{11,12,15,16,20,21,23}$ were among the commonly reported risk factors of stroke based on the included studies (Table 4).

\section{DISCUSSION}

The review has only found one study measuring the national incidence of stroke among Filipinos annually for four years. ${ }^{21}$ Selection bias and outcome bias were also noted in the appraisal of evidence; thus, judgment and caution in the use of these data should be considered.

Meanwhile, results showed a prevalence of stroke of as low as $0.486 \%$ to as high as $6 \%$. While the range is relatively

Table 3. Prevalence of stroke according to subtypes ${ }^{11-14}$

\begin{tabular}{|c|c|c|c|c|}
\hline Study ID & Ischemic & Hemorrhagic & $\begin{array}{c}\text { Transient } \\
\text { Ischemic Attack }\end{array}$ & Others \\
\hline Guieb, $1988^{13}$ & $51.0 \%$ & $37.4 \%$ & $4.7 \%$ & $6.9 \%$ \\
\hline Dayrit, $2004^{11}$ & $78.0 \%$ & $22.0 \%$ & - & - \\
\hline Carcel, $2009^{23}$ & $68.6 \%$ & $31.4 \%$ & - & - \\
\hline Ong, $2011^{14}$ & $26.0 \%$ & $14.0 \%$ & - & $60 \% *$ \\
\hline
\end{tabular}

* Others in this study refer to patients manifesting symptoms of a cerebrovascular disease but cannot be classified due to lack of CT scan result 
Table 4. Prevalence of risk factors of stroke among included studies

\begin{tabular}{|c|c|c|c|c|c|c|c|c|c|c|c|c|}
\hline \multirow{2}{*}{ Study ID } & \multicolumn{2}{|c|}{ Hypertension } & \multicolumn{2}{|c|}{ Current smoker } & \multicolumn{2}{|c|}{$\begin{array}{l}\text { DM by FBG with } \\
\text { or without history }\end{array}$} & \multicolumn{2}{|c|}{$\begin{array}{l}\text { Cholesterol } \\
>200 \mathrm{mg} / \mathrm{dL}\end{array}$} & \multicolumn{2}{|c|}{$\mathrm{LDL}>130 \mathrm{mg} / \mathrm{dL}$} & \multicolumn{2}{|c|}{$\begin{array}{c}\text { Obesity } \\
(\mathrm{BMI}>30)\end{array}$} \\
\hline & $\begin{array}{l}\text { Preva- } \\
\text { lence }\end{array}$ & $95 \% \mathrm{Cl}$ & $\begin{array}{l}\text { Preva- } \\
\text { lence }\end{array}$ & $95 \% \mathrm{Cl}$ & $\begin{array}{l}\text { Preva- } \\
\text { lence }\end{array}$ & $95 \% \mathrm{Cl}$ & $\begin{array}{l}\text { Preva- } \\
\text { lence }\end{array}$ & $95 \% \mathrm{Cl}$ & $\begin{array}{l}\text { Preva- } \\
\text { lence }\end{array}$ & $95 \% \mathrm{Cl}$ & $\begin{array}{l}\text { Preva- } \\
\text { lence }\end{array}$ & $95 \% \mathrm{Cl}$ \\
\hline Guieb, $1988^{13}$ & 68.9 & - & - & - & 21.6 & - & - & - & - & - & - & - \\
\hline Sy, $2003^{19}$ & 17.2 & - & - & - & 4.0 & - & 16.0 & - & 24.0 & - & - & - \\
\hline Dayrit $2004^{11}$ & 56.0 & - & 36.0 & - & 5.7 & - & - & - & - & - & - & - \\
\hline Dans, $2005^{16}$ & 17.4 & - & 34.8 & - & 4.6 & - & 28.0 & - & 31.5 & - & 4.8 & 4.8 \\
\hline Soria, $2007^{22}$ & - & - & - & - & 12.0 & $9.95-14.28$ & - & - & - & - & - & - \\
\hline Carcel, $2009^{23}$ & 69.3 & - & 7.9 & - & 27.9 & - & - & - & 100.0 & - & - & - \\
\hline Sy, $2012^{20}$ & 20.6 & $19.4-21.8$ & 31.0 & $29.1-32.9$ & 5.2 & $3.1-7.3$ & 10.2 & $9.45-10.95$ & 11.8 & $11.0-12.6$ & 3.6 & $0.2-7$ \\
\hline Garcia, 2014 12 & 54.1 & - & 46.5 & - & 11.4 & - & 36.8 & - & 12.4 & - & - & - \\
\hline Abola, $2017^{21}$ & 87.44 & - & 7.08 & - & 46.23 & - & 61.91 & - & - & - & 7.44 & - \\
\hline Castillo, $2019^{15}$ & 34.3 & - & 12.2 & - & 6.2 & - & - & - & - & - & - & - \\
\hline
\end{tabular}

wide, possible sources of variation may have to do with the way stroke was identified among study participants. While most studies utilized a questionnaire, the survey questions varied from one study to another. For instance, the study of Sy in 1998 centered on questions regarding the history of weakness in one side of the body while another study by Roxas Jr. in 2003 probed on a previous diagnosis of stroke by a health professional. ${ }^{18,19}$ The highest prevalence reported was noted in the study of Sy, while the lowest prevalence was recorded in a community survey by Navarro (2005). ${ }^{17,19}$ Age distribution has not been discussed in these studies. Thus, younger subjects who had fewer stroke risks or older individuals with more risk factors may have been surveyed more, resulting in either a decreased or increased prevalence, respectively. Also, no conclusive trend was observed as to whether a structured questionnaire for diagnosing stroke or self-reporting of the previous diagnosis of stroke resulted in over- or underestimation of the prevalence. This may be partly due to the different sensitivity and specificity of survey questions used.

In a study conducted by Avan et al. looking at the epidemiology of stroke and socioeconomic status, the 2017 prevalence rate of stroke for all types in lower-to-middle income countries (LMICs) was reported to be at 1,076.8 per 100,000 persons or $1.08 \% .{ }^{29}$ This value fits within the range of prevalence values obtained from the various studies and is close to the reported values of Sy. ${ }^{20}$ The study of Castillo, on the other hand, specifically a survey conducted in 2017, reported a much higher prevalence of $2.6 \%$, which may have been possible due to a general trend of the increasing number of stroke cases. ${ }^{15}$

In terms of the risk factors associated with stroke, these are generally considered known and well-studied in the Philippines. One study by Sy revealed that the stroke risk factors among Filipinos are not that different from other countries, especially among LMICs. ${ }^{20}$ Despite these risk factors being known, only a few effective measures have been instituted to control them.

Repeated surveys showed rising trends in the prevalence of these risk factors. For instance, the prevalence of hypertension increased from $17.2 \%$ in 1998 to $34.3 \%$ in 2017 , while the prevalence of diabetes increased from $4 \%$ to $6.2 \%$ in the same years. ${ }^{15,19}$ Despite government programs and health campaigns, the prevalence of hypertension and diabetes mellitus among Filipinos remains high. Furthermore, the majority of patients diagnosed with stroke were found to be hypertensive, with proportions ranging from 54.1\%-87.44\%, suggesting that hypertensive disease plays a key risk factor for strokes, especially those of hemorrhagic etiology. ${ }^{2}$ Also, the proportion of stroke patients with diabetes mellitus and high cholesterol were found to be $46.23 \%$ and $61.91 \%$ respectively, in one study. ${ }^{21}$

While this review has identified prevalence/incidence studies of stroke in the Philippine context, we have determined several limitations. First, the search included only published articles with available full-text, specifically those with archives maintained by the Philippine Council for Health Research and Development through the HERDIN Database. Hence, publication bias should be considered when using the results of this study. Second, due to the heterogeneity of study characteristics such as case definition of stroke, and study participants as well as reported outcomes for risk factors, we were not able to conduct a meta-analysis to pool the outcomes of interest. However, even if there are limitations to this review, the assessment of the risk of bias in included studies can help guide the readers in determining which studies have reliable information.

\section{CONCLUSIONS}

Based on this systematic review, the national stroke incidence rate ranges from $3.95 \%$ to $5.61 \%$ based on a multiyear data of one study, while the national stroke prevalence rate ranges from $0.486 \%$ to $6.0 \%$. For incidence study, selection bias and outcome bias were noted in the appraisal of evidence; thus, judgment and caution in using these data should be considered. Hypertension remains the commonly reported risk factor of stroke, among others. Diabetes and smoking were also identified as top risk factors. Noting the variability of data and the limited studies on the national epidemiology 
of stroke in the Philippines, it is recommended that the national government consider establishing a system such as a national registry for better data collection and analysis. This national registry can serve as an online repository of patient data for more accurate analysis and epidemiological estimates. Although there have been initiatives within the hospitals to track stroke cases through sustaining a stroke registry and, to some extent, a national survey to measure the prevalence of stroke, government support remains essential.

\section{Acknowledgment}

The authors extend their gratitude to the Department of Science and Technology - Philippine Council for Health Research and Development (DOST-PCHRD) for its support in providing access to full texts of archived studies in HERDIN.

\section{Statement of Authorship}

The authors concepted and designed; data acquisition, analysis, and interpretation; drafting, revising, and final approval of the manuscript; agree to be accountable for all aspects of the work.

All authors participated in data collection, analysis, writing and approval of the final version submitted.

\section{Author Disclosure}

The reviewers have no relevant affiliations or financial involvement with any organization or entity with a financial interest or in financial conflict with the subject matter or materials discussed in this report.

All authors declared no conflicts of interest.

\section{Funding Source}

This study did not obtain any specific grant from funding agencies in the public, commercial, or nonprofit sectors.

\section{REFERENCES}

1. Philippine Statistics Authority. 2015 vital statistics report [Internet]. 2015. [cited: 2020 March 30]. Available from: https://psa.gov.ph/sites/ default/files/2015 VSR Vol.2 FINAL_signed FOREWORD.pdf

2. Philippine Statistics Authority. Registered deaths in the Philippines, 2017 [Internet]. [cited: 2020 March 30]. Philippine Statistics Authority. 2019. Available from: https://psa.gov.ph/vital-statistics/id/138794.

3. Department of Health. The 2016 Philippine health statistics [Internet]. 2016. [cited: 2020 March 30]. Available from: https://www.doh.gov. ph/sites/default/files/publications/2016_PHILIPPINE-HEALTHSTATISTICS.pdf

4. Department of Health. National objectives for health Philippines, 2017-2022 [Internet]. 2018.[cited: 2020 March 30]. Available from: https://www.doh.gov.ph/sites/default/files/publications/NOH-20172022-030619-1.pdf

5. Navarro JC, Baroque AC, Lokin JK, Venketasubramanian N. The real stroke burden in the Philippines. Int J Stroke. 2014 Jul; 9(5):640-641. DOI: $10.1111 /$ ijs.12287.

6. Moher D. Preferred reporting items for systematic reviews and meta-analyses: the PRISMA statement. Ann Intern Med. 2009 Aug18;151(4):264-269, W64. DOI: 10.7326/0003-4819-151-4200908180-00135.
7. Wells G, Shea B, O'Connell D, J Peterson, V Welch, M Losos The Newcastle-Ottawa Scale (NOS) for assessing the quality of nonrandomised studies in meta-analyses. 2013. http://www.ohri.ca/ programs/clinical_epidemiology/oxford.asp (accessed 30 March 2020)

8. Hoy D, Brooks P, Woolf A, Blyth F, March L, Bain C, et al. Assessing risk of bias in prevalence studies: modification of an existing tool and evidence of interrater agreement. J Clin Epidemiol. 2012 Sep;65(9):934-939. DOI: 10.1016/j.jclinepi.2011.11.014.

9. Downes MJ, Brennan ML, Williams HC, Dean RS. Development of a critical appraisal tool to assess the quality of cross-sectional studies (AXIS). BMJ Open. 2016 Dec 8;6(12):e011458. DOI: 10.1136/ bmjopen-2016-011458.

10. Penson DF, Krishnaswami S, Jules A, Seroogy JC, McPheeters ML. Evaluation and Treatment of Cryptorchidism. Comparative Effectiveness Review No. 88. (Prepared by the Vanderbilt Evidencebased Practice Center under Contract No. 290-2007-10065-I.) AHRQ Publication No. 13-EHC001-EF. Rockville, MD: Agency for Healthcare Research and Quality. December 2012. www. effectivehealthcare.ahrq.gov/reports/final.cfm.

11. Dayrit GD, Aquino AV, Tolentino ML, Cuanang JR, San Jose,CZ. Risk factors and outcome analysis among young Filipino patients with nontraumatic intracerebral hemorrhage: a cross-sectional study. The Philippine Journal of Neurology 2004 June;8(1):7-16.

12. Garcia R, De Leon J, Virola-Leh MA. Prevalence of stroke and associated risk factors among adult Filipino patients of President Diosdado Macapagal Memorial Medical Center, January 1-December 31, 2012. The Filipino Family Physician 2014 April-June;52(2):81-91.

13. Guieb MA, Perez MC. Epidemiologic assessment of stroke. Makati Medical Center Proceedings 1988;2:48-52.

14. Ong VM, Nitafan CZ, Avenido LN, Reburiano DP. Morning surge of blood pressure associated with increase incidence of cerebrovascular accidents in a tertiary hospital. Journal of Philippine Medical Association 2011;89:69-82.

15. Castillo RR, Atilano AA, David-Ona DI, Granada CN, Sevilla MR, Torreblanca H. May measurement month 2017: an analysis of blood pressure screening in the Philippines-South-East Asia and Australasia. Eur Heart J Suppl 2019 Apr; 21(Suppl D):D92-D96. DOI: 10.1093/eurheartj/suz066.

16. Paz-Pacheco E, Velandria FV, Villarruz MV, Roxas A, Sy RA, Morales DD, Amarillo L, Abola TB, Punzalan FE, Dans AL. National nutrition and health survey (NNHeS): Atherosclerosis-Related Diseases and Risk Factors. Philippine Journal of Internal Medicine 2005 May; 43(3):103-115

17. Navarro JC. Prevalence of stroke: a community survey. The Philippine Journal of Neurology 2005 November; 9(2):11-15.

18. Roxas A, Gose M, Dominguez J, Liban S, Rosales R, Sosa M. The prevalence of stroke, parkinsonism, dementia, migraine, and epilepsy in the Philippines. Part I: The validation of the PNA questionnaire. The Philippine Journal of Neurology 2007 January-June;11(1):1-4.

19. Sy RG, Dans AL, Velandria F, Abola TB, Roxas AA, Punzalan FE. The prevalence of dyslipidemia, diabetes, hypertension, stroke, and angina pectoris in the Philippines. Philippine Journal of Internal Medicine 2003;41:1-6.

20. Sy RG, Morales DD, Dans AL, Pacheco EP, Punzalan FE, Abelardo NS. Prevalence of atherosclerosis-related risk factors and diseases in the Philippines. J Epidemiol 2012;22(5):440-447. DOI:10.2188/jea. JE20110095.

21. Abola MT, Punzalan FE. Four-year clinical outcomes of Filipino patients with or at risk for atherothrombotic events from the REACH registry. Philippine Journal of Internal Medicine 2017 JulySeptember;55(3):1-8.

22. Ty-Willing T, Soria MLJB, Velandria FV, Vega BS. Philippine cardiovascular outcome study-diabetes mellitus (PhilCOS-DM): The eight-year incidence of diabetes mellitus and other cardiovascular outcomes of the 1998 FNRI-NNS, in the NCR, Region 3 and Region 4. Philippine Journal of Cardiology 2007;35:10-21.

23. Carcel C, Espiritu-Picar R. Circadian variation of ischemic and hemorrhagic strokes in adults at a tertiary hospital: a retrospective study. J Neurol Sci 2009;13:45-51. 
24. Singh RB, Suh IL, Singh VP, Chaithiraphan, Laothavorn P, Sy R. Hypertension and stroke in asia: prevalence, control and strategies in developing countries for prevention. J Hum Hypertens 2000 OctNov;14(10-11):749-763. DOI: 10.1038/sj.jhh.1001057.

25. Khor GL. Cardiovascular epidemiology in the Asia-Pacific region. Asia Pac J Clin Nutr 2001;10(2):76-80. DOI: 10.1111/j.14406047.2001.00230.x.

26. Sison J, Divinagracia R, Nailes J. Asian management of hypertension: Current status, home blood pressure, and specific concerns in Philippines (a country report). The Journal of Clinical Hypertension 2020 February; 22(3). DOI:10.1111/jch.13802.

27. Venketasubramanian N, Yoon BW, Pandian J, Navarro J. Stroke epidemiology in south, east, and south-east Asia: A Review. J Stroke 2017 Sep;19(3):286-294. DOI: 10.5853/jos.2017.00234.
28. Goto S, Ikeda Y, Chan JCN, Wilson PW, Cheng Yeo T, Liau CS. Risk factor profile, drug usage and cardiovascular events within a year in patients with and at high risk of atherothrombosis recruited from Asia as compared with those recruited from non-Asian regions: a substudy of the REduction of Atherothrombosis for Continued Health (REACH) registry. Heart Asia 2011;3(1):93-98. DOI: 10.1136/ ha.2010.002691.

29. Avan A, Digaleh H, Napoli MD, Stranges S, Behrouz R, Shojaejanbabaei G. Socioeconomic status and stroke incidence, prevalence, mortality, and worldwide burden: an ecological analysis from the Global Burden of Disease Study 2017. BMC Med 2019 Oct;17(1):191. DOI: 10.1186/s12916-019-1397-3.

\section{APPENDICES}

Appendix Table 1. General characteristics of included studies

\begin{tabular}{|c|c|c|c|c|c|}
\hline Study ID & Study Design & Study Duration & Study Participants & $\begin{array}{l}\text { No. of Study } \\
\text { Participants }\end{array}$ & $\begin{array}{l}\text { Method for Diagnosing } \\
\text { or Identifying Stroke }\end{array}$ \\
\hline Navarro, 2005 & $\begin{array}{l}\text { Cross-sectional study } \\
\text { design, Community- } \\
\text { based survey }\end{array}$ & $\begin{array}{l}\text { June - December } \\
1999\end{array}$ & Adults aged 18 and above & 19,113 & $\begin{array}{l}\text { Questionnaire } \\
\text { consisting of } 4 \text { items }\end{array}$ \\
\hline Roxas Jr., 2007 & $\begin{array}{l}\text { Cross-sectional study } \\
\text { using a multistage } \\
\text { cluster sampling }\end{array}$ & 2003 & Adults aged 20 and above & 4,753 & $\begin{array}{l}\text { Self-reporting of } \\
\text { previous diagnosis } \\
\text { of stroke }\end{array}$ \\
\hline Sy, 2012 & $\begin{array}{l}\text { Cross-sectional study } \\
\text { design, stratified } \\
\text { multistage sampling }\end{array}$ & 2008 & Adults aged 20 and above & 7700 & $\begin{array}{l}\text { Questionnaire via face- } \\
\text { to-face interview (prior } \\
\text { diagnosis by medical } \\
\text { doctor or nurse of stroke }\end{array}$ \\
\hline Soria, 2007 & $\begin{array}{l}\text { Descriptive cohort } \\
\text { study }\end{array}$ & 2006 & $\begin{array}{l}\text { Respondents of the } 1998 \text { FNRI-NNS } \\
\text { survey of the National Capital Region, } \\
\text { Region } 3 \text { and Region } 4\end{array}$ & 1,099 & Questionnaire \\
\hline Sy, 2003 & $\begin{array}{l}\text { Cross-sectional } \\
\text { national survey }\end{array}$ & 1998 & Adults aged 20 and above & 4,541 & $\begin{array}{l}\text { Questionnaire, based on } \\
\text { single criterion which } \\
\text { queried on history of } \\
\text { sudden weakness on } \\
\text { one side of the body }\end{array}$ \\
\hline Ong, 2010 & $\begin{array}{l}\text { Descriptive cross- } \\
\text { sectional study }\end{array}$ & 2009 & $\begin{array}{l}\text { Patients diagnosed with cerebro- } \\
\text { vascular disease, with elevated blood } \\
\text { pressure of } 140 / 90 \text { and above, } \\
\text { regardless of medication status and } \\
\text { compliance. Patients were excluded } \\
\text { if with renal failure, hepatic damage, } \\
\text { obvious present illness, DM, past } \\
\text { history of CAD, previous stroke, CHF, } \\
\text { and arrhythmia }\end{array}$ & 170 & Hospital records \\
\hline Guieb, 1988 & $\begin{array}{l}\text { Descriptive cross- } \\
\text { sectional study }\end{array}$ & $\begin{array}{l}\text { January 1, } 1987 \text { - } \\
\text { August } 15,1987\end{array}$ & $\begin{array}{l}\text { Patients admitted at Makati Medical } \\
\text { Center with diagnosis of stroke }\end{array}$ & 190 & Hospital records \\
\hline Dayrit, 2004 & Cross-sectional study & $\begin{array}{l}\text { January } 1999 \text { - } \\
\text { March } 2003\end{array}$ & $\begin{array}{l}\text { Patients diagnosed with stroke aged } \\
45 \text { years and below and admitted at } \\
\text { an urban tertiary medical center }\end{array}$ & 1,950 & $\begin{array}{l}\text { Hospital records and } \\
\text { questionnaire }\end{array}$ \\
\hline Castillo, 2019 & Cross-sectional study & May 2017 & Adults aged 18 and above & 271,604 & Screening questionnaire \\
\hline Carcel, 2009 & Retrospective cohort & $\begin{array}{l}\text { January 1, } 2008- \\
\text { May } 31,2008\end{array}$ & $\begin{array}{l}\text { Patients diagnosed with stroke } \\
\text { aged } 21 \text { years and above }\end{array}$ & 165 & $\begin{array}{l}\text { Hospital records and } \\
\text { patient charts }\end{array}$ \\
\hline Garcia, 2014 & $\begin{array}{l}\text { Descriptive cross- } \\
\text { sectional study }\end{array}$ & $\begin{array}{l}\text { January 1, } 2012- \\
\text { December 31, } 2012 \\
\end{array}$ & $\begin{array}{l}\text { Patients diagnosed with stroke } \\
\text { aged } 18 \text { years and above }\end{array}$ & 185 & $\begin{array}{l}\text { Hospital records and } \\
\text { questionnaire }\end{array}$ \\
\hline Dans, 2005 & $\begin{array}{l}\text { Cross-sectional study } \\
\text { using a stratified multi- } \\
\text { stage cluster sampling }\end{array}$ & $\begin{array}{l}\text { August } 2003- \\
\text { December } 2003\end{array}$ & $\begin{array}{l}\text { Adult Filipinos aged } 20 \text { years } \\
\text { and above }\end{array}$ & 4,753 & $\begin{array}{l}\text { Patient history and } \\
\text { validated questionnaire }\end{array}$ \\
\hline Abola, 2017 & Prospective cohort & $2004-2008$ & $\begin{array}{l}\text { Filipino outpatients aged } 45 \text { years } \\
\text { and above }\end{array}$ & 1,040 & $\begin{array}{l}\text { Patient records and } \\
\text { follow-up questionnaire }\end{array}$ \\
\hline
\end{tabular}


Appendix Table 2. Risk of bias assessment among included studies

Table 2A. Risk of bias assessment (AXIS) for non-prevalence cross-sectional studies Study ID

Guieb, 1988 Ong, 2011 Dayrit, 2004 Garcia, 2014 Introduction

1. Were the aims/objectives of the study clear? Methods

2. Was the study design appropriate for the stated aim(s)?

3. Was the sample size justified?

4. Was the target/reference population clearly defined? (Is it clear who the research was about?)

5. Was the sample frame taken from an appropriate population base so that it closely represented the target/reference population under investigation?

6. Was the selection process likely to select subjects/participants that were representative of the target/reference population under investigation?

7. Were measures undertaken to address and categorize non-responders?

8. Were the risk factor and outcome variables measured appropriate to the aims of the study?

9. Were the risk factor and outcome variables measured correctly using instruments/ measurements that had been trialed, piloted, or published previously?

10. Is it clear what was used to determine statistical significance and/or precision estimates? (e.g., p-values, confidence intervals)

11. Were the methods (including statistical methods) sufficiently described to enable them to be repeated?

\section{Results}

12. Were the basic data adequately described?

13. Does the response rate raise concerns about non-response bias?

14. If appropriate, was information about non-responders described?

15. Were the results internally consistent?

16. Were the results presented for all the analyses described in the methods?

Discussion

17. Were the authors' discussions and conclusions justified by the results?

18. Were the limitations of the study discussed?

Other

19. Were there any funding sources or conflicts of interest that may affect the authors' interpretation of the results?

20. Was ethical approval or consent of participants attained?

$\begin{array}{llll} & & \\ Y & Y & Y & Y\end{array}$

\begin{tabular}{|c|c|c|c|}
\hline Y & $\mathrm{N}$ & $\mathrm{N}$ & $Y$ \\
\hline$N$ & $\mathrm{~N}$ & $\mathrm{~N}$ & $\mathrm{~N}$ \\
\hline Y & $Y$ & $Y$ & $Y$ \\
\hline $\mathrm{N}$ & $\mathrm{N}$ & $\mathrm{N}$ & $\mathrm{Y}$ \\
\hline $\mathrm{N}$ & $\mathrm{N}$ & $\mathrm{N}$ & $\mathrm{N}$ \\
\hline NA & NA & NA & NA \\
\hline$Y$ & $Y$ & $\mathrm{Y}$ & $\mathrm{Y}$ \\
\hline$Y$ & $Y$ & $Y$ & $Y$ \\
\hline $\mathrm{N}$ & $Y$ & $Y$ & $\mathrm{~N}$ \\
\hline$Y$ & $Y$ & $Y$ & $\mathrm{~N}$ \\
\hline
\end{tabular}

\begin{tabular}{cccc}
$Y$ & $Y$ & $Y$ & $Y$ \\
$N$ & $N$ & $N$ & $N$ \\
$N A$ & $N A$ & $N A$ & $N A$ \\
$Y$ & $Y$ & $Y$ & $Y$ \\
$N$ & $Y$ & $Y$ & $N$ \\
\hline
\end{tabular}

$\mathrm{N}$

$\begin{array}{llll}\mathrm{Y} & \mathrm{N} & \mathrm{Y} & \mathrm{Y}\end{array}$

$\mathrm{Y} \quad \mathrm{N}$

Y

$\mathrm{N}$

Table 2B. Risk of bias assessment (Newcastle Ottawa Scale) for cohort studies Study ID Soria, 2007 Abola, 2017 Carcel, 2009

\begin{tabular}{lll}
\multirow{3}{*}{ Selection } & Representativeness of the Exposed Cohort \\
\cline { 2 - 3 } & Selection of the Exposed Cohort \\
\cline { 2 - 3 } & Ascertainment of Exposure \\
\cline { 2 - 3 } $\begin{array}{l}\text { Demonstration that the Outcome of } \\
\text { Interest was not present at start of study }\end{array}$ \\
\hline Comparability & $\begin{array}{l}\text { Comparability of Cohorts on the Basis of } \\
\text { Design or Analysis }\end{array}$ \\
\hline Outcome & Assessment of Outcome & \\
\cline { 2 - 3 } & $\begin{array}{l}\text { Was follow-up long enough for outcomes } \\
\text { to occur? }\end{array}$ & \\
\cline { 2 - 3 } & Adequacy of follow-up of cohorts & \\
\hline Overall Quality of Study & Poor quality Poor quality Poor quality \\
\hline
\end{tabular}


Philippine Stroke Epidemiology

Table 2C. Risk of bias assessment (Quality Assessment Checklist) for prevalence cross-sectional studies

\begin{tabular}{|c|c|c|c|c|c|c|}
\hline Study ID & Dans, 2005 & Castillo, 2019 & Navarro, 2005 & Roxas Jr., 2007 & Sy 2012 & Sy, 2003 \\
\hline $\begin{array}{l}\text { Was the study target population a close representation of } \\
\text { the general population in relation to relevant variables? }\end{array}$ & 0 & 0 & 1 & 0 & 0 & 0 \\
\hline $\begin{array}{l}\text { Was the sampling frame a true or close representation of } \\
\text { the target population? }\end{array}$ & 0 & 1 & 1 & 0 & 0 & 0 \\
\hline $\begin{array}{l}\text { Was some form of random selection used to select the } \\
\text { sample, OR, was a census undertaken? }\end{array}$ & 0 & 1 & 0 & 0 & 0 & 0 \\
\hline Was the likelihood of nonresponse bias minimal? & 0 & 0 & 0 & 0 & 0 & 1 \\
\hline $\begin{array}{l}\text { Were data collected directly from the subjects (as opposed } \\
\text { to a proxy)? }\end{array}$ & 0 & 0 & 0 & 0 & 0 & 0 \\
\hline Was an acceptable case definition used in the study? & 0 & 0 & 0 & 0 & 0 & 0 \\
\hline $\begin{array}{l}\text { Was the study instrument that measured the parameter of } \\
\text { interest shown to have validity and reliability? }\end{array}$ & 0 & 1 & 0 & 0 & 0 & 0 \\
\hline Was the same mode of data collection used for all subjects? & 0 & 0 & 0 & 0 & 0 & 0 \\
\hline $\begin{array}{l}\text { Was the length of the shortest prevalence period for the } \\
\text { parameter of interest appropriate? }\end{array}$ & 0 & 0 & 1 & 0 & 0 & 1 \\
\hline $\begin{array}{l}\text { Were the numerator(s) and denominator (s) for the } \\
\text { parameter of interest appropriate }\end{array}$ & 0 & 0 & 0 & 0 & 0 & 0 \\
\hline Overall Risk of Bias & Low risk & Low risk & Low risk & Low risk & Low risk & Low risk \\
\hline
\end{tabular}

